\title{
The Association between Chronic Use of Renin-Angiotensin- Aldosterone System Blockers and in-Hospital Adverse Events among COVID-19 Patients with Hypertension
}

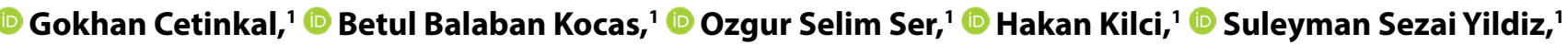 \\ (1) Safiye Nur Ozcan, ${ }^{2}$ () Yildiz Verdi, ${ }^{2}$ [D Mustafa Altinay, ${ }^{3}$ () Kadriye Kilickesmez'
}

'Department of Cardiology, University of Health Sciences Turkey, Sisli Hamidiye Etfal Teaching and Research Hospital, Istanbul, Turkey ${ }^{2}$ Department of Infectious Diseases and Clinical Microbiology, University of Health Sciences Turkey, Sisli Hamidiye Etfal Teaching and Research Hospital, Istanbul, Turkey

${ }^{3}$ Department of Anesthesiology and Reanimation, University of Health Sciences Turkey, Sisli Hamidiye Etfal Teaching and Research Hospital, Istanbul, Turkey

\begin{abstract}
Objectives: The effects of chronic renin-angiotensin-aldosterone system (RAAS) blockers usage on adverse outcomes and disease severity remain uncertain in COVID-19 patients with hypertension. In this study, we aimed to determine the relationship between chronic use of RAAS inhibitors and in-hospital adverse events among hypertensive patients hospitalized with COVID-19. Methods: In this retrospective single-center study, we enrolled 349 consecutive hypertensive patients diagnosed with COVID-19 infection. All patients were chronically on angiotensin-converting enzyme inhibitors (ACEI)/ angiotensin II receptor blockers (ARB) or other antihypertensive therapies before hospital admission. Adverse clinical events were defined as in-hospital mortality, admission to intensive care unit, need for high-flow oxygen and intubation.

Results: Patients were categorized into two groups according to the type of antihypertensive therapy. (ACEI/ARBs users, N=201; ACEI/ARB nonusers, $\mathrm{N}=148$ ) There was no statistically significant difference between $\mathrm{ACEl} / \mathrm{ARBs}$ users and ACEl/ARBs nonusers concerning adverse clinical events, such as in-hospital mortality (29 (14.4\%) vs. 20 (13.5\%), p=0.81), ICU admission (45(22.4\%) vs. $27(18.2 \%), p=0.34)$, need for high-flow oxygen (97 (48.3\%) vs. $68(45.9 \%), p=0.67)$ and need for intubation (32(15.9\%) vs. $23(15.5 \%), p=0.92)$, respectively. Also, the severity of infection did not differ among groups. The logistic regression multivariate analysis showed that age, neutrophil-lymphocyte ratio, procalcitonin and ferritin levels were independent predictors of in-hospital mortality.

Conclusion: Our results suggest that chronic use of ACEI/ARBs did not increase in-hospital adverse outcomes of hypertensive patients hospitalized with COVID-19. Although the recent data are contradictory, chronic ACEI/ARB therapy is not recommended to be discontinued in hypertensive patients during their hospitalization for COVID-19.

Keywords: COVID-19; hypertension; RAAS blockers; mortality; adverse clinical outcomes.

Please cite this article as "Cetinkal G, Balaban Kocas B, Ser OS, Kilci H, Sezai Yildiz SS, Ozcan SN, et al. The Association between Chronic Use of Renin-Angiotensin-Aldosterone System Blockers and in-Hospital Adverse Events among COVID-19 Patients with Hypertension. Med Bull Sisli Etfal Hosp 2020;54(4):399-404".
\end{abstract}

Address for correspondence: Gokhan Cetinkal, MD. Sisli Hamidiye Etfal Tip Uygulama ve Arastirma Merkezi, Saglik Bilimleri Universitesi, Istanbul, Turkey

Phone: +90 2123735000 E-mail: gokhancetinkal@yahoo.com

Submitted Date: September 03, 2020 Accepted Date: September 26, 2020 Available Online Date: December 11, 2020

${ }^{\circ}$ Copyright 2019 by The Medical Bulletin of Sisli Etfal Hospital - Available online at www.sislietfaltip.org

OPEN ACCESS This is an open access article under the CC BY-NC license (http://creativecommons.org/licenses/by-nc/4.0/). 
$T_{\text {resilna }}^{\text {he }}$ he viral outbreak that arises from a new severe acute respiratory syndrome coronavirus 2 (SARS-CoV-2) has currently emerged as a public health crisis since it has been declared as a pandemic in March, 2020. Defining the risk factors associated with severe coronavirus disease 2019 (COVID-19) had become a major current focus of researchers due to the increasing number of confirmed cases and the rapid spread of the virus.

In most of the reports, patients with comorbidities, such as older age, hypertension (HTN), diabetes mellitus (DM) and cardiovascular diseases, were identified as more susceptible to the COVID-19 infection. ${ }^{[1,2]}$ Besides, HTN was reported as the most prevalent comorbidity of the COVID-19 and related to increased mortality. ${ }^{[3]}$ Renin-angiotensinaldosterone system (RAAS) inhibitors are one of the firstline drugs used in hypertensive patients worldwide. It has been hypothesized that angiotensin-converting enzyme inhibitors (ACEI)/angiotensin II receptor blockers (ARB) may upregulate the expression of ACE2 receptor, the direct entrance for the SARS-CoV-2, thus facilitate the penetration of the virus into the lung cells. ${ }^{[4,5]}$ This issue has recently attracted the attention of researchers, as RAAS inhibitors are commonly used among hypertensive patients hospitalized for COVID-19. Inversely, Kuba et al. ${ }^{[6]}$ showed that expression of the ACE-2 receptor is downregulated following SARS-CoV-1 infection, causing RAAS hyperactivation and deterioration of pneumonia. Hence, it has been assumed that the use of ACEI/ARBs may be beneficial by the downregulation of ACE2 receptor expression and inhibition of RAAS hyperactivation after SARS-CoV-2 infection.

The emerging data concerning the association between the use of ACEI/ARB and mortality in hypertensive patients with COVID-19 is still indefinite. Some reports suggested that $\mathrm{ACEl} / \mathrm{ARB}$ usage may be related to disease progression and increased risk of death during hospitalization for COVID-19. [7, ${ }^{8]}$ On the contrary, it was reported that ACE2 converts angiotensin II, which is a proinflammatory vasoconstrictive and fibrotic agent, into angiotensin, thereby protecting the lungs from acute injury. ${ }^{[9]}$ Thus, ACEl/ARBs may also ensure a benefit via this mechanism throughout the therapy. Based on these conflicting results, we aimed to investigate the association between chronic use of RAAS blockers and in-hospital adverse clinical outcomes among hospitalized COVID-19 patients with HTN. Besides, a comprehensive evaluation of this issue may provide the optimal antihypertensive treatment strategy during the hospitalization of these patients.

\section{Methods}

In this study, 349 patients with HTN hospitalized for COVID-19 from March 10, 2020 to May 10,2020 were enrolled in our single-center study, and the data were retrospectively analyzed. The patients with the lack of in-hospital clinical data and the absence of pre-admission antihypertensive medication records were excluded from this study. Diagnosis of COVID-19 infection was confirmed with using reverse-transcription polymerase chain reaction together with symptoms, clinical signs and specific viral pneumonia findings on computerized thoracic tomography. All patients were treated according to the guidelines of National Health Ministry constituted for COVID-19. Antihypertensive medications of all subjects were checked from National Medical Record System using Social Security Institution website. Chronic usage was defined as regularly receiving ACEl/ARBs before hospital admission.

Demographic, laboratory and clinical information were collected from electronic medical records. Demographic and clinical data included age, gender, presence of DM, HTN, hyperlipidemia ( $\mathrm{HL})$, smoking status, congestive heart failure, prior cardiovascular disease, stroke, chronic obstructive pulmonary disease (COPD), chronic renal disease, malignancy and length of hospital stay. The laboratory data, including complete blood count and detailed biochemistry parameters, were collected within the first week of hospital admission. The neutrophil to lymphocyte ratio (NLR) was calculated by dividing the neutrophil count by the lymphocyte count. Severe infection was identified by the presence of any of the following: respiratory rate $\geq 30$ breaths/min; blood oxygen saturation $\leq 93 \%$; $\mathrm{PaO} 2 / \mathrm{FiO} 2$ ratio $<300$; $>50 \%$, lesion progress in 24 to 48 hours showed by lung imaging, respiratory failure necessitating mechanical ventilation and admission to the intensive care unit. ${ }^{[10]}$

Study population was divided into two groups according to the type of antihypertensive therapy; group 1, ACEI/ARB users ( $n=201)$; group 2, ACEI/ARB nonusers $(n=148)$. Adverse clinical endpoints were defined as in-hospital mortality, intensive care unit (ICU) admission, need for high-flow oxygen and invasive mechanical ventilation therapy (intubation). This study complied with the edicts of the 1975 Declaration of Helsinki and was approved by the local ethics committee (22.04.2020/2734).

\section{Statistical Analysis}

Continuous variables were reported as median and interquartile ranges, while categorical variables are presented as percentages. The Kolmogorov-Smirnov test was performed to test the normality of distributions. The Student t-test or Mann-Whitney $U$ test for continuous variables and the chi-square test for categorical variables were used for comparison of the study groups. Independent predictors of in-hospital mortality were determined by the logistic regression analysis. A goodness-of-fit test for our model was performed using the Hosmer-Lemeshow method to evaluate differences between the model-predicted and 
observed event rates. $C$ statistics were used to assess the predictive ability of the model used in logistic regression analysis. Values of $p<0.05$ were considered statistically significant. SPSS 22 software (SPSS Inc, Chicago, Illinois, USA) was used to perform all statistical analysis.

\section{Results}

The types of antihypertensive medications used in our study population were 41 (11.7\%) ACEI only, 14 (4\%) ARB only, $44(12.6 \%)$ combination of ACEI and diuretic, 50 (14.3\%) combination of ARB and diuretic, 31 (8.9\%) combination of ACEI and calcium channel blocker (CCB), 20 (5.7\%) combination of $A R B$ and $C C B, 6(1.7 \%)$ combination of ACEl, diuretic and CCB, 88 (25.2\%) CCB only, 60 (17.2\%) others (alpha blockers, beta-blockers and other antihypertensives), respectively.

Table 1 and Table 2 demonstrated the demographic, clinical features, and laboratory parameters of the subjects. There was no difference between the groups concerning

Table 1. The clinical and demographic features of the study population

\begin{tabular}{|c|c|c|c|}
\hline & $\begin{array}{c}\text { ACEI/ARB } \\
\text { users } \\
(n=201)\end{array}$ & $\begin{array}{c}\text { ACEI/ARB } \\
\text { nonusers } \\
(n=148)\end{array}$ & $\mathbf{p}$ \\
\hline Age, years & $69.5(60-77)$ & $68(58-76.8)$ & 0.68 \\
\hline Male gender & $100(49.8)$ & $76(51.4)$ & 0.67 \\
\hline Diabetes mellitus & $81(40.3)$ & $60(40.5)$ & 0.96 \\
\hline Hypercholesterolemia & $70(34.8)$ & $29(19.6)$ & 0.002 \\
\hline Smoking & $35(17.4)$ & $29(19.6)$ & 0.61 \\
\hline Previous CVD & $85(42.3)$ & $55(37.2)$ & 0.33 \\
\hline COPD & $38(18.9)$ & $19(12.6)$ & 0.13 \\
\hline Congestive heart failure & $21(10.4)$ & $17(11.5)$ & 0.76 \\
\hline Chronic kidney disease & $22(10.9)$ & $33(22.3)$ & 0.004 \\
\hline Previous stroke & $15(7.5)$ & $11(7.4)$ & 0.99 \\
\hline Previous malignancy & $17(8.5)$ & $19(12.8)$ & 0.18 \\
\hline Length of hospital stay, days & $8(6-12)$ & $8(6-12)$ & 0.89 \\
\hline Severe infection & $67(33.3)$ & $39(26.4)$ & 0.16 \\
\hline In-hospital death & $29(14.4)$ & $20(13.5)$ & 0,81 \\
\hline ICU admission & $45(22.4)$ & $27(18.2)$ & 0.34 \\
\hline Intubation & $32(15.9)$ & $23(15.5)$ & 0.92 \\
\hline $\begin{array}{l}\text { High flow oxygen demand } \\
\text { In-hospital medications }\end{array}$ & $97(48.3)$ & $68(45.9)$ & 0.67 \\
\hline Hydroxychloroquine & $199(99)$ & $146(98.6)$ & 0.76 \\
\hline Oseltamivir & $100(49.8)$ & $87(58.8)$ & 0.09 \\
\hline Favipravir & $39(19.4)$ & $22(14.9)$ & 0.27 \\
\hline Azithromycin & $47(23.4)$ & $32(21.6)$ & 0.69 \\
\hline Lopinavir/Ritonavir & $9(4.5)$ & $3(2)$ & 0.21 \\
\hline
\end{tabular}

ACEl: angiotensin-converting enzyme inhibitor; ARB: angiotensin II receptor blocker; CVD: cardiovascular disease; COPD: chronic obstructive pulmonary disease; ICU: intensive care unit. age, gender, length of hospital stay, smoking status, history of DM, HTN, HL, stroke, cardiovascular disease, congestive heart failure, malignancy and COPD. The incidence of chronic kidney disease was significantly higher in the ACEI/ ARB nonusers group, whereas the incidence of $\mathrm{HL}$ was significantly higher in the ACEI/ARB users group. There were no differences concerning the rates of severe infection, in hospital mortality, intensive care unit admission, invasive mechanic ventilation and high flow oxygen demand between the groups. COVID-19 specific medications were similar between the groups during hospitalization. All biochemical characteristics and laboratory parameters of the study groups were also similar except aspartate aminotransferase levels.

The results of univariate and multivariate logistic regression analysis are presented in Table 3. A multivariate logistic regression analysis was performed for in hospital mortality, based on the following variables: NLR, male gender, age, DM, cardiovascular disease, heart failure, use of RAAS blockers, chronic kidney disease, smoking, COPD, D-dimer, lactate dehydrogenase, procalcitonin and ferritin levels.

Table 2. Biochemical characteristics and laboratory parameters of the study population

\begin{tabular}{|c|c|c|c|}
\hline & $\begin{array}{c}\text { ACEI/ARB } \\
\text { users } \\
(n=201)\end{array}$ & $\begin{array}{c}\text { ACEI/ARB } \\
\text { nonusers } \\
(n=148)\end{array}$ & $\mathbf{p}$ \\
\hline Troponin I (ng/dl) & $10(5-36)$ & $11(4-38)$ & $0.54^{*}$ \\
\hline CK-MB (ng/dl) & $2(1-4)$ & $2(1-3)$ & $0.17^{*}$ \\
\hline D-dimer $(\mu \mathrm{g} / \mathrm{ml})$ & $743.5(515.3-1330)$ & $780(512.8-1580)$ & $0.44^{*}$ \\
\hline White blood cell $\left(/ \mathrm{mm}^{3}\right)$ & 6405 (4735-9052) & 6765 (5042-8700) & $0.51^{*}$ \\
\hline Neutrophil $\left(/ \mathrm{mm}^{3}\right)$ & $4370(3042-6782)$ & 4695 (3607-6875) & $0.34^{*}$ \\
\hline Lymphocyte $\left(/ \mathrm{mm}^{3}\right)$ & $1180(760-1647)$ & $1100(805-1557)$ & $0.67^{*}$ \\
\hline NLR & $3.9(2.3-7.2)$ & $4.3(3.6-6.5)$ & 0.39 \\
\hline Hemoglobin (gr/dl) & $12.7(11-14)$ & $12.5(11-14)$ & $0.57^{*}$ \\
\hline Platelet $\left(\times 10^{3} / \mathrm{mm}^{3}\right)$ & $175(149-238)$ & $184(152-262)$ & 0,67 \\
\hline Urea (mg/dl) & $42(31-58)$ & $41.5(30-74)$ & $0.79 *$ \\
\hline Creatinine (mg/dl) & $0.95(0.75-1.27)$ & $0.98(0.79-1.53)$ & $0.23^{*}$ \\
\hline AST (U/L) & $26(19-41)$ & $22(17-32)$ & $0.005^{*}$ \\
\hline $\operatorname{ALT}(\mathrm{U} / \mathrm{L})$ & $25(17-38)$ & $23(14-33)$ & $0.13^{*}$ \\
\hline Glucose (mg/dl) & $124(108-172)$ & $124(105-159)$ & $0.29 *$ \\
\hline $\mathrm{LDH}(\mathrm{U} / \mathrm{L})$ & $257(216-330)$ & $258(214-308)$ & $0.79 *$ \\
\hline Ferritin (ng/ml) & $140(73-406)$ & $180(70-450)$ & $0.45^{*}$ \\
\hline CRP (mg/dl) & $38(15-99)$ & $46(15-97)$ & $0.93^{*}$ \\
\hline Procalcitonin(ng/ml) & $0.12(0.11-0.23)$ & $0.12(0.11-0.37)$ & $0.10^{*}$ \\
\hline APTT (seconds) & $25.5(24-27)$ & $26(23-27)$ & $0.95^{*}$ \\
\hline
\end{tabular}

*Mann-Whitney U test; ACEl: angiotensin-converting enzyme inhibitor; ARB: angiotensin II receptor blocker; ALT: alanine aminotransferase; AST: aspartate aminotransferase; APTT: activated partial thromboplastin time; CK-MB: creatine kinase myocardial band; $C R P: C$ reactive protein; $\mathrm{LDH}$ : lactate dehydrogenase; NLR: neutrophil to lymphocyte ratio. 
Table 3. Univariable and multivariable predictors of in-hospital mortality

\begin{tabular}{|c|c|c|c|c|}
\hline & \multicolumn{2}{|c|}{ Univariate } & \multicolumn{2}{|c|}{ Multivariate } \\
\hline NLR & $1.11(1.06-1.16)$ & $<0.001$ & $1.07(1.02-1.13)$ & 0.004 \\
\hline Male gender & $1.45(0.79-2.66)$ & 0.22 & $1.34(0.61-2.98)$ & 0.48 \\
\hline Age, years & $1.04(1.01-1.07)$ & 0.004 & $1.05(1.01-1.09)$ & 0.009 \\
\hline Diabetes mellitus & $1.24(0.67-2.28)$ & 0.49 & $1.44(0.67-3.09)$ & 0.35 \\
\hline Heart failure & $2.49(1.12-5.52)$ & 0.03 & $2.40(0.82-7.01)$ & 0.11 \\
\hline Use of RAAS blockers & $1.08(0.58-1.99)$ & 0.81 & $1.57(0.72-3.46)$ & 0.26 \\
\hline Chronic kidney disease & $1.94(0.94-4.01)$ & 0.07 & $1.34(0.52-3.43)$ & 0.54 \\
\hline Smoking & $0.71(0.31-1.67)$ & 0.43 & $1.14(0.39-3.29)$ & 0.82 \\
\hline COPD & $0.68(0.28-1.68)$ & 0.41 & $0.56(0.19-1.72)$ & 0.31 \\
\hline
\end{tabular}

$\mathrm{Cl}$ : confidence interval; COPD: chronic obstructive pulmonary disease; LDH: lactate dehydrogenase; NLR: neutrophil to lymphocyte ratio; RAAS: reninangiotensin-aldosterone system.

Among these variables, NLR, age, procalcitonin and ferritin levels were identified as independent predictors of inhospital mortality. The predictive ability of our model was evaluated using $C$ statistics and had a good discriminative capacity in predicting in-hospital death (C statistics 0.82 , $95 \%$ confidence interval $0.77-0.88, p<0.001)$. Non-significant result from the Hosmer-Lemeshow test demonstrated that the calibration of our model to predict in-hospital death was accurate in our study $(p=0.35)$.

\section{Discussion}

The results of our study suggest that chronic use of ACEI/ ARBs did not increase the rates of adverse clinical outcomes, such as in-hospital death, ICU admission, high-flow oxygen and intubation demand in hypertensive patients hospitalized for COVID-19. Also, ACEI/ARBs did not worsen the severity of the infection compared with other antihypertensives. Additionally, we found that age, NLR, procalcitonin and ferritin levels were independent predictors of in-hospital mortality.

ACE-2 receptor, which is an inhibitor of RAAS and a potential entry point for SARS-CoV-2, is prominently increased in cardiopulmonary circulation with the use of ACE inh/ARBs. ${ }^{[11]}$ Therefore, it was hypothesized that patients with COVID-19 who had been chronically on ACE inh/ARB treatment might be at increased risk of adverse clinical outcomes during the hospital stay. ${ }^{[12]}$ Likewise, a recent study conducted by Selcuk et al. ${ }^{[13]}$ demonstrated increased in-hospital mortality among COVID-19 patients with HTN receiving RAAS blockers. Different from our study, their ACEI/ARB nonuser group was younger, had fewer comorbidities, and the incidence of coronary artery disease was lower. However, the mortality rate was significantly higher that may be explained by the enrollment of patients with higher risk, differences in treatment strategies or delayed hospital admission besides ACEI/ARB usage. Also, their study was conducted with a relatively small sample-sized population that these results may differentiate with including much more patients.

Conversely, it has been speculated that the downregulation of ACE2 receptor expression due to COVID-19 infection may lead to excessive RAS activation and clinical deterioration of pneumonia. Thus, ACEI/ARB treatment may enable benefit using inhibiting RAS hyperactivation and thus preventing lung damage. Felice et al. ${ }^{[14]}$ demonstrated that ACEI/ARBs did not worsen the adverse events in COVID-19 and even may be useful for pneumonia prevention. Patients in ACEI/ARB nonusers were significantly older and had a higher history of chronic heart failure compared with ACEI/ARB users. This may also explain why the incidence of ICU admission is significantly lower in ACEI/ARB group, besides the protective role of ACEI/ARBs, similarly, Senkal et al. ${ }^{[15]}$ conducted a study in hypertensive COVID-19 patients and demonstrated that the risk of severe infection was significantly reduced by ACEI exposure. ACEI exposure was also associated with milder infection signs, like diminished infiltrations seen on baseline computerized tomography images, lower CRP and ferritin levels and decreased length of hospital stay. Likewise, previous studies ${ }^{[3,16]}$ reported 
that RAAS inhibitors were not related to increased mortality in hypertensive patients during hospitalization for COVID-19. A meta-analysis ${ }^{[17]}$ demonstrated that in-hospital use of ACEI/ARB was associated with a lower risk of mortality. However, no information was given about the initiation time of ACEI/ARB treatment or how long the patients used them. Therefore, differing from these studies, we aimed to investigate the effects of chronic use of RAAS blockers on adverse events.

Older age, DM, HTN and prior cardiovascular disease are confirmed to be prognostic risk factors in patients hospitalized with COVID-19. ${ }^{[18]} \mathrm{NLR}$ is commonly increased among patients with COVID-19 and increased NLR is appeared to show a worse prognosis. ${ }^{[19,20]}$ Besides, as the severe systemic inflammation parameters like procalcitonin and ferritin levels increased, the incidence of adverse events also increased in COVID-19. ${ }^{[21]}$ Consistent with the literature, age, NLR, procalcitonin and ferritin levels were independent predictors of in-hospital mortality according to our results. In this respect, the cytokine storm induced by severe infection may be the main underlying reason for increased in-hospital mortality rather than ACEI/ARB use. Hence, a detailed evaluation and closer follow-up of patients with severe infection signs should be established during the hospital stay.

\section{Limitations}

Our study presents some limitations: it was a retrospective, modest sample-sized study performed in a single center. As our study was conducted in a definite geographic region, these results cannot be generalized to all patients with COVID-19.

\section{Conclusion}

Our results suggest that chronic use of RAAS blockers did not associate with an increased risk of in-hospital adverse events among hypertensive patients hospitalized with COVID-19. Besides, in accordance with recommendations of societies and current guidelines. there is no evidence to support the cessation of such therapies during hospitalization. Further prospective studies are needed to elucidate the underlying protective mechanism of RAAS blockers and confirm our findings in a larger cohort of patients.

\section{Disclosures}

Ethics Committee Approval: This study complied with the edicts of the 1975 Declaration of Helsinki and was approved by the local ethics committee (22.04.2020/2734).

Peer-review: Externally peer-reviewed.

Conflict of Interest: None declared.
Authorship Contributions: Concept - G.C., B.B.B., O.S.S., K.K.; Design - K.K., H.K., S.N.C., Y.V., M.A.; Supervision - G.C., B.B.K., K.K.; Materials - S.N.C., Y.V., M.A., O.S.S., H.K.; Data collection \&/or processing - S.N.C., M.A., O.S.S., H.K.; Analysis and/or interpretation O.S.S., M.A., H.K., S.S.Y.; Literature search - H.K., S.N.C., Y.V.; Writing - G.C., B.B.K., S.S.Y.; Critical review - S.S.Y.

\section{References}

1. Chen R, Liang W, Jiang M, Guan W, Zhan C, Wang T, et al; Medical Treatment Expert Group for COVID-19. Risk Factors of Fatal Outcome in Hospitalized Subjects With Coronavirus Disease 2019 From a Nationwide Analysis in China. Chest 2020;158:97-105.

2. Petrilli CM, Jones SA, Yang J, Rajagopalan H, O'Donnell L, Chernyak $Y$, et al. Factors associated with hospital admission and critical illness among 5279 people with coronavirus disease 2019 in New York City: prospective cohort study. BMJ 2020;369:m1966. [CrossRef]

3. Zhang P, Zhu L, Cai J, Lei F, Qin JJ, Xie J, et al. Association of Inpatient Use of Angiotensin-Converting Enzyme Inhibitors and Angiotensin II Receptor Blockers With Mortality Among Patients With Hypertension Hospitalized With COVID-19. Circ Res 2020;126:1671-81. [CrossRef]

4. Zhou $P$, Yang XL, Wang XG, Hu B, Zhang L, Zhang W, et al. A pneumonia outbreak associated with a new coronavirus of probable bat origin. Nature 2020;579:270-3.

5. Hoffmann M, Kleine-Weber $H$, Schroeder S, Krüger N, Herrler T, Erichsen $S$, et al. SARS-CoV-2 Cell Entry Depends on ACE2 and TMPRSS2 and Is Blocked by a Clinically Proven Protease Inhibitor. Cell 2020;181:271-80. [CrossRef]

6. Kuba K, Imai Y, Rao S, Gao H, Guo F, Guan B, et al. A crucial role of angiotensin converting enzyme 2 (ACE2) in SARS coronavirusinduced lung injury. Nat Med 2005;11:875-9. [CrossRef]

7. Fang $L$, Karakiulakis $G$, Roth $M$. Are patients with hypertension and diabetes mellitus at increased risk for COVID-19 infection? Lancet Respir Med 2020;8:e21. [CrossRef]

8. Zheng YY, Ma YT, Zhang JY, Xie X. COVID-19 and the cardiovascular system. Nat Rev Cardiol 2020;17:259-60. [CrossRef]

9. Bavishi C, Maddox TM, Messerli FH. Coronavirus Disease 2019 (COVID-19) Infection and Renin Angiotensin System Blockers. JAMA Cardiol 2020;5:745-7. [CrossRef]

10. WHO. Report of the WHO-China Joint Mission on Coronavirus Disease 2019. Available at: https://www.who.int/docs/defaultsource/coronaviruse/who-china-joint-mission-on-covid-19-finalreport.pdf. Accessed Oct 20, 2020.

11. Ferrario CM, Jessup J, Chappell MC, Averill DB, Brosnihan KB, Tallant $E A$, et al. Effect of angiotensin-converting enzyme inhibition and angiotensin II receptor blockers on cardiac angiotensin-converting enzyme 2. Circulation 2005;111:2605-10. [CrossRef]

12. Vaduganathan M, Vardeny $O$, Michel T, McMurray JJV, Pfeffer MA, Solomon SD. Renin-Angiotensin-Aldosterone System Inhibitors in Patients with Covid-19. N Engl J Med 2020;382:1653-9. [CrossRef] 13. Selçuk M, Çınar T, Keskin M, Çiçek V, Kılıç Ş, Kenan B, et al. Is the use 
of ACE inb/ARBs associated with higher in-hospital mortality in Covid-19 pneumonia patients? Clin Exp Hypertens 2020;42:73842. [CrossRef]

14. Felice C, Nardin C, Di Tanna GL, Grossi U, Bernardi E, Scaldaferri $\mathrm{L}$, et al. Use of RAAS inhibitors and risk of clinical deterioration in COVID-19: results from an Italian cohort of 133 hypertensives. Am J Hypertens 2020 Jun 8 [Epub ahead of print], doi: 10.1093/ajh/ hpaa096. [CrossRef]

15. Şenkal N, Meral R, Medetalibeyoğlu A, Konyaoğlu H, Kose M, Tukek T. Association between chronic ACE inhibitor exposure and decreased odds of severe disease in patients with COVID-19. Anatol J Cardiol 2020;24:21-9.

16. Li J, Wang X, Chen J, Zhang H, Deng A. Association of ReninAngiotensin System Inhibitors With Severity or Risk of Death in Patients With Hypertension Hospitalized for Coronavirus Disease 2019 (COVID-19) Infection in Wuhan, China. JAMA Cardiol 2020;5:825-30. [CrossRef]

17. Flacco ME, Acuti Martellucci C, Bravi F, Parruti G, Cappadona R,
Mascitelli A, et al. Treatment with ACE inhibitors or ARBs and risk of severe/lethal COVID-19: a meta-analysis. Heart 2020;106:151924. [CrossRef]

18. Li X, Xu S, Yu M, Wang K, Tao Y, Zhou Y, et al. Risk factors for severity and mortality in adult COVID-19 inpatients in Wuhan. J Allergy Clin Immunol 2020;146:110-8. [CrossRef]

19. Liu Y, Du X, Chen J, Jin Y, Peng L, Wang HHX, et al. Neutrophil-tolymphocyte ratio as an independent risk factor for mortality in hospitalized patients with COVID-19. J Infect 2020;81:e6-12.

20. Yan X, Li F, Wang X, Yan J, Zhu F, Tang S, et al. Neutrophil to lymphocyte ratio as prognostic and predictive factor in patients with coronavirus disease 2019: A retrospective cross-sectional study. J Med Virol. 2020 May 26 [Epub ahead of print], doi: 10.1002/ jmv.26061. [CrossRef]

21. Zeng F, Huang Y, Guo Y, Yin M, Chen X, Xiao L, Deng G. Association of inflammatory markers with the severity of COVID-19: A metaanalysis. Int J Infect Dis 2020;96:467-74. [CrossRef] 